\title{
Practical Conclusions
}

Conclusions emerging from this experiment are as follows.

(1) That most kinds of glass in common use are opaque to X-rays.

(2) That small fragments of the order of $\frac{1}{2}-2 \mathrm{~mm}$. in thickness show an opacity when exposed through the thickness of the eye and eyelids, and in addition through the thickness of the skull, but that fragments of under $1 \mathrm{~mm}$. in thickness may be difficult of detection in such conditions.

(3) It may be concluded that pieces of glass actually in the eye or orbit and exposed to X-rays under comparable conditions would also show, but that having regard to the somewhat greater distance of the foreign particles from the film in such a case, fragments of under $1 \mathrm{~mm}$. in thickness would a fortiori, be difficult of detection.

\section{Summary}

The object of the experiment is stated and the reasons given which led to its inception.

The details and mode of conduct are described.

The limitations of the experiment are discussed.

A classified list of the glasses used in the experiment is given.

The results of the experiment are given, and the practical conclusions are drawn, which appear to emerge therefrom.

\section{REFERENCES}

1. Parsons.-Diseases of the Eye. Seventh edition, p. 431.

2. Shanks, Kerley and Twining (1938). - A Text-book of X-ray Diagnosis, Vol. III, p. 746.

3. BAKER (1939). - Kadiography. October, 1937, p. 140.

\section{A SIMPLE OPTICAL APPLIANCE FOR USE WITH RESPIRATORS}

BY

$$
\begin{aligned}
& \text { P. Kinmont, M.D., F.R.C.S.Ed., A.D.M.S., E.M.S. } \\
& \text { newark-on-trent }
\end{aligned}
$$

THEIRE must be many hypermetropic presbyopes like myself, who have sought in vain for spectacles to wear inside the general service and civilian duty respirators which permit clear vision for reading and writing messages etc. 
I have tried many makes of flat-sided spectacles for wearing inside the respirators, only to find that:-

(a) The pressure on the bridge of the nose is painful.

(b) The slightest tilting of the bifocal lenses causes distortion.

(c) The dimming is an intolerable nuisance.

These factors necessitate removal of the mask from time to time, which is of course undesirable.

My optician has adopted my suggestion to remedy these faults and has succeeded to a gratifying degree.

The principle is simplicity itself, and consists of an outer flat steel spring, attached to which is an inner eye-wire to carry the requisite visual correction. The whole fitting is worn outside the mask eyepiece, and the spring is kept in position by its own

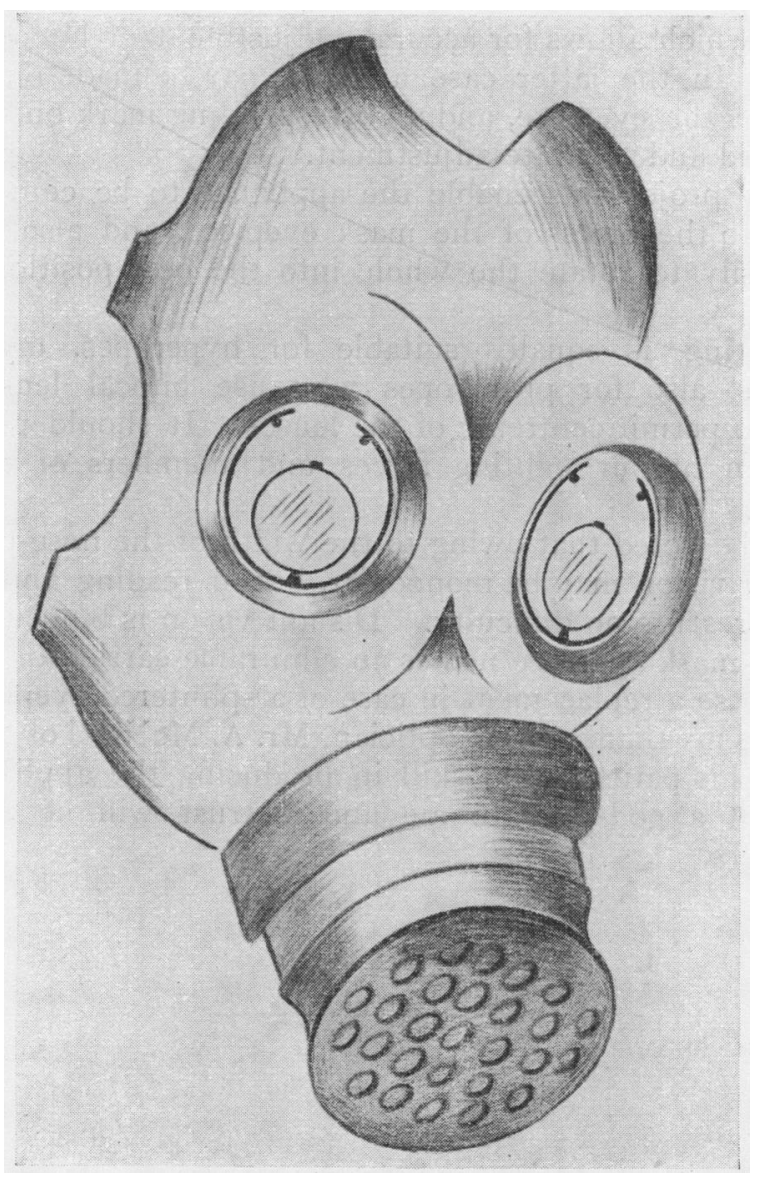




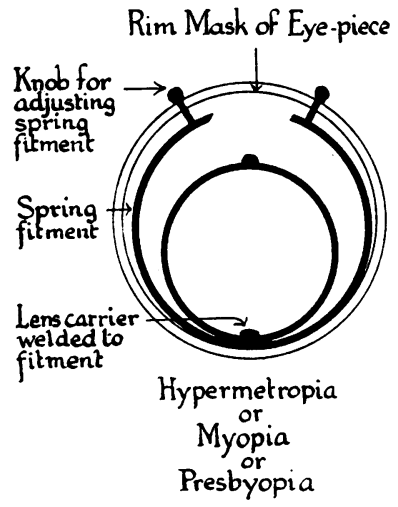

I

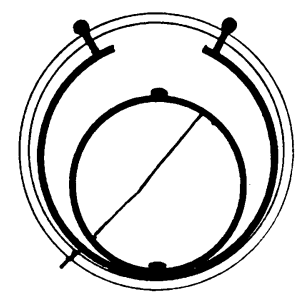

Astigmatics

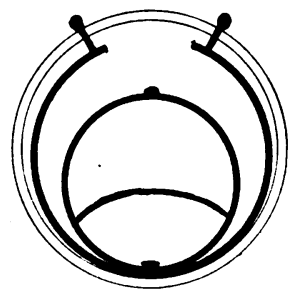

Bifocals

elasticity, which allows for accurate adjustment of bifocal lenses or cylinders. In the latter case a mark may be made on the metal surround of the eyepiece, and a corresponding mark on the lens to ensure rapid and accurate adjustment.

The two projections enable the appliance to be contracted and planted into the recess of the mask eyepiece, and also enable the wearer easily to rotate the whole into the best position for clear vision.

The fitting is equally suitable for hyperopes, myopes, and astigmatics, also for presbyopes who use bifocal lenses and is designed to permit centreing of the lenses. It should prove useful to the men of our fighting forces and members of the A.R.P. Services.

It is to be noted that owing to the width of the nose-piece of the mask, near vision may be monocular, but in reading and writing, I find this presents no difficulty. Distant vision is binocular.

A spare mask eyepiece makes an admirable carrier for the fitment and of course a replacement in case of a splintered eyepiece.

I express my thanks to my optician, Mr. A. McNicol of Newark-onTrent, for his patience and skill in producing the appliance which has proved a god-send to me and I trust will be of help to many others. 